Ahmed T. Hassan, Ehssan S. Hassan*, and Oday M. Abdulmunem

\title{
Effect of thermal annealing on the structural and optical properties of $\mathrm{TiO}_{2}$ nanostructures ${ }^{* *}$
}

https://doi.org/10.1515/jmbm-2021-0033

Received Jul 27, 2021; accepted Jan 13, 2022

\begin{abstract}
In this work, TiO nanostructure films were deposited via vacuum thermal evaporation at a temperature of $80^{\circ} \mathrm{C}$. The TiO thin films were annealed under vacuum for $1 \mathrm{~h}$ at three different degrees $\left(200,300\right.$, and $\left.400^{\circ} \mathrm{C}\right)$ in addition to the thin film prepared at $80^{\circ} \mathrm{C}$. X-ray Diffraction (XRD) showed that all the deposited and annealed TiO films had anatase polycrystalline diffraction patterns with a predominant reflection of the (200) plane. As a result, the particle size increased with annealing temperature. Scanning Electron Microscopy (SEM) measurements showed that at the annealed temperature of $200^{\circ} \mathrm{C}$, the shape of the TiO nanostructures began to change from a condensed cluster distribution to a conical shape. As the annealing temperature was increased to $400^{\circ} \mathrm{C}$, all the conical shapes transformed into clear spherical shapes. The spherical shapes recorded $45(\mathrm{~nm})$ height and (20) (nm) base width. Optical measurements were performed using Ultraviolet-Visible spectroscopy (UV-Vis). The transmittance is reduced from $79.63 \%$ for the $\mathrm{TiO}$ sample prepared at $80^{\circ} \mathrm{C}$ to $71.91 \%$ for the TiO sample annealed at $400^{\circ} \mathrm{C}$. The optical energy gap values decrease from $3.279 \mathrm{eV}$ for the prepared $\mathrm{TiO}$ sample at $80^{\circ} \mathrm{C}$ to $3.115 \mathrm{eV}$ for the TiO sample annealed at $400^{\circ} \mathrm{C}$.
\end{abstract}

Keywords: Titanium dioxide nanostructures, Thermal evaporation technique, Clusters like hemispherical

\footnotetext{
${ }^{\star}$ Corresponding Author: Ehssan S. Hassan: Department of
Physics, College of Science, Mustansiriyah University, Baghdad,

^Corresponding Author: Ehssan S. Hassan: Department of
Physics, College of Science, Mustansiriyah University, Baghdad, Iraq; Email: ehsanphysicyan@uomustansiriyah.edu.iq Ahmed T. Hassan: Ministery of Education, Directorate General for Education, Iraq, Baghdad

Oday M. Abdulmunem: Department of Physics, College of Science, Mustansiriyah University, Baghdad, Iraq

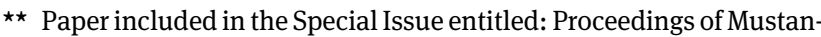
siriyah International Conference on Applied Physics - 2021 (MICAP2021), https://www.micap.uomustansiriyah.edu.iq
}

¿ Open Access. ( 2021 A. T. Hassan et al., published by De Gruyter. (cc) BY 4.0 License

\section{Introduction}

Over the last 30 years, there has been extensive work focused on producing titanium oxide nanoparticles (TiO NPs) due to their low production cost, high efficiency [1], and use in a wide array of scientific applications such as photo electronic sensors [2]. Transition metal semiconductors, such as $\mathrm{ZnO}$ [3], $\mathrm{CuO}$ [4], $\mathrm{SnO}$ [5], and $\mathrm{FeO}$ [6], while titanium oxide is important because it has a wide energy gap of 3.0$3.6 \mathrm{eV}$, which makes it a compelling option for applications requiring a dielectric material. Titanium dioxide $\left(\mathrm{TiO}_{2}\right)$ is a negatively conductive $n$-type semiconductor material due to intrinsic defects in the crystal structure of the lattice [7].

Titanium dioxide can be present in multiple crystal phases, such as anatase (tetragonal), rutile (tetragonal), and brookite (orthorhombic) [8]. It can also exist in an amorphous solid state. The anatase phase has an energy gap of $3.0 \mathrm{eV}-3.2 \mathrm{eV}$, and its electrons are high mobility, making it suitable for photocatalytic and antibacterial applications [9]. This phase is also stable at high temperatures. The rutile phase has an energy gap of $3.2 \mathrm{eV}-3.4 \mathrm{eV}$.

TiO NPs can be produced by multiple methods, including sol-gel [10], Direct Current (DC) sputtering and Radio Frequency (RF) sputtering [11], thermal evaporation [12], and spray pyrolysis [13-16]. In the present research, TiO films were produced through thermal evaporation, where TiO was used in the form of powder, and the evaporation boat was composed of molybdenum. The novelty of this research lies in examining the relationship between the annealing temperature and the resulting titanium oxide nanostructures Thus, we can determine different applications depending on the resulting nanostructures.

\section{Materials and methods}

Titanium oxide powder with a purity of $99.99 \%$ was placed in a molybdenum boat to prepare titanium oxide films by thermal evaporation. An increase in the current (0-300 Amp) raised the temperature almost about $\left(0.26^{\circ} \mathrm{C} / \mathrm{W}\right)$ inside the chamber leading to increase the pressure in the 
vacuum chamber $\approx\left(1 \times 10^{-5}-1 \times 10^{-2}\right.$ mbar $)$. The material was deposited on the surface of the glass substrate, which was installed at $15 \mathrm{~cm}$ away from the evaporation boat at an angle of $\theta=30^{\circ}$. Further, a deposition rate of $2(\mathrm{~nm}) \cdot \mathrm{s}^{-1}$ was used.

\section{Results and discussion}

Figure 1 shows the XRD patterns of titanium oxide prepared by thermal evaporation under vacuum at a temperature of $80^{\circ} \mathrm{C}$ (as deposited) and those for the samples annealed at 200,300 , and $400^{\circ} \mathrm{C}$ for $1 \mathrm{~h}$. In Figure 1, the matching diffraction pattern for all TiO samples is anatase polycrystalline were identical to the international card 43-1269, with a predominant reflection of the (200) plane at $2 \theta=43.57^{\circ}$. The intensity of the reflection increases with increased annealing temperature as can be seen from Figure 1(a). The relationship of the full width at half maximum (FWHM) with the annealing temperature for all samples decreases with increased annealing temperature. This indicates an increase in the crystallite size [17], as shown in Figure 2(a). The calculation of the FWHM was done using Origin graphing software. The crystallite size was calculated using the Debye-Scherer equation. The values of the FWHM and the crystallite size have been recorded in Table 1. Figures 2(c and d) present the macrostrain and the dislocation density as a function of annealing temperatures [18].

Several secondary reflections of the planes (111), (220), (311), (222) and (400) correspond to $2 \theta=37.40^{\circ}, 62.70^{\circ}$, $75.13^{\circ}, 79.37^{\circ}$ and $94.28^{\circ}$.

The macrostrain and dislocation density values decrease with increased annealing temperature because of the increase in crystallization and the decrease in crystal defects, macrostrain and the dislocation density values recorded in Table 1.

Figures 3(a, b, c, and d) depict the SEM micrographs of samples (as deposited, 200, 300, and $400^{\circ} \mathrm{C}$ ) for $1 \mathrm{~h}$. Figures 3(a1, b1, c1, and d1) are the schematics of the grain growth samples of titanium dioxide prepared by thermal

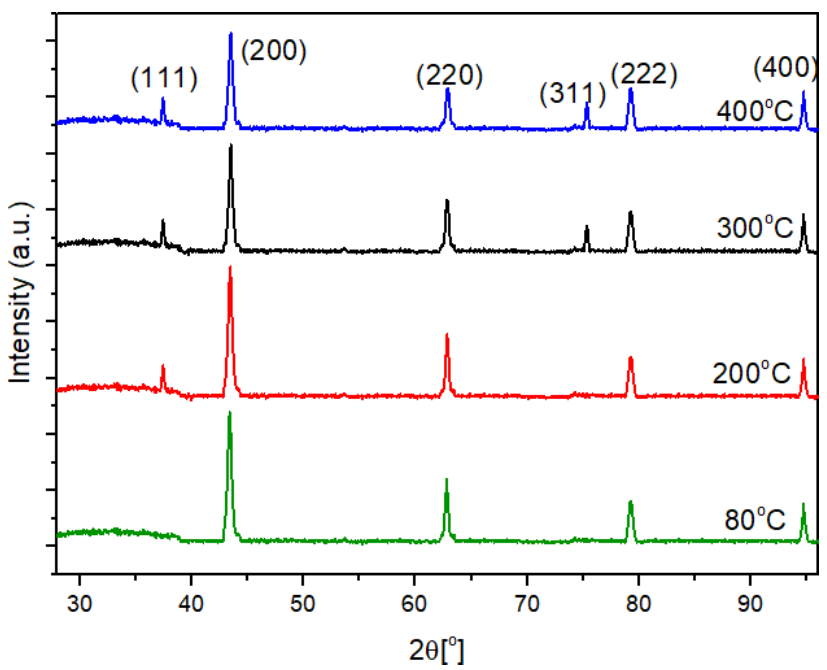

Figure 1: X-ray diffraction pattern of titanium oxide of deposited at $80^{\circ} \mathrm{C}$ and annealed at temperatures of 200,300 and $400^{\circ} \mathrm{C}$
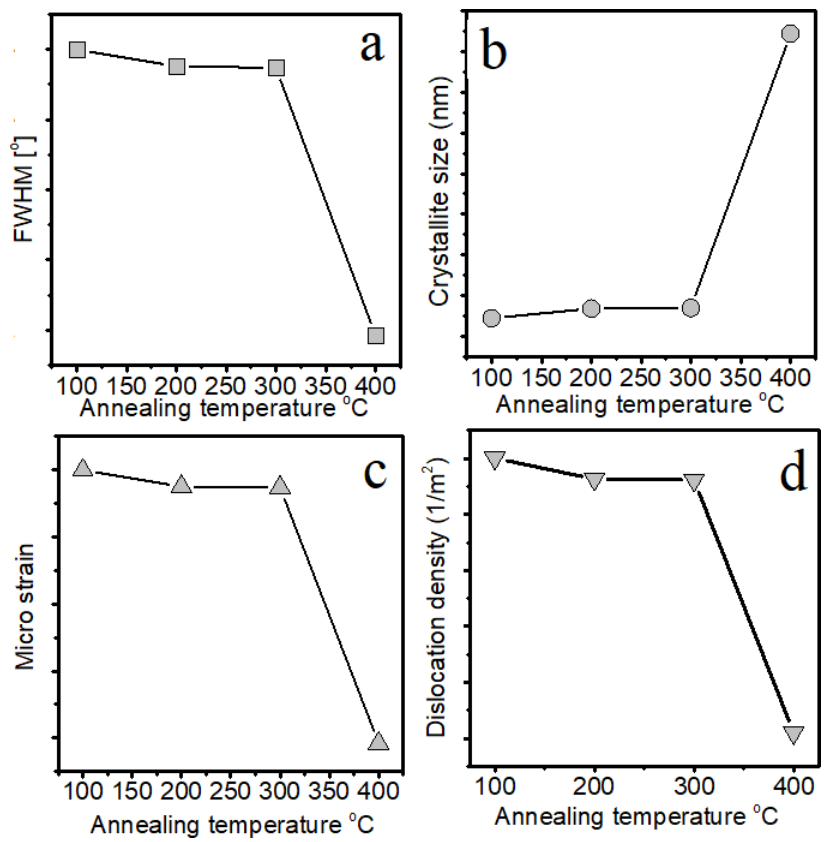

Figure 2: (a) Crystallite size, (b) Full width at half maximum, (c) Dislocation density and (d) Microstrain of titanium oxide as a function of annealing temperature at the dominate reflection

Table 1: XRD result and structural parameters for TiO films prepared by thermal evaporation under a vacuum

\begin{tabular}{ccccccc}
\hline $\begin{array}{c}\text { Annealing } \mathbf{T} . \\
{ }^{\circ} \boldsymbol{C}\end{array}$ & (hkl) plane & $\begin{array}{c}\mathbf{2 \theta} \\
\boldsymbol{I}^{\circ} \boldsymbol{J}\end{array}$ & $\begin{array}{c}\boldsymbol{F W H M} \\
(\mathbf{d e g} .)\end{array}$ & $\begin{array}{c}\text { Crystallite size } \\
(\mathbf{n m})\end{array}$ & Micro strain & $\begin{array}{c}\text { Dislocation density } \\
\left(\mathbf{1} / \mathbf{m}^{\mathbf{2}}\right) \times \mathbf{1 0}^{\mathbf{1 4}}\end{array}$ \\
\hline $\mathbf{8 0}$ & $(200)$ & 30.12 & 0.415 & 16.89 & 9.843 & 10.483 \\
$\mathbf{2 0 0}$ & $(200)$ & 43.87 & 0.314 & 17.36 & 17.481 & 33.064 \\
$\mathbf{3 0 0}$ & $(200)$ & 43.29 & 0.236 & 17.39 & 17.505 & 33.155 \\
$\mathbf{4 0 0}$ & $(200)$ & 43.75 & 0.221 & 30.88 & 17.992 & 35.027 \\
\hline
\end{tabular}



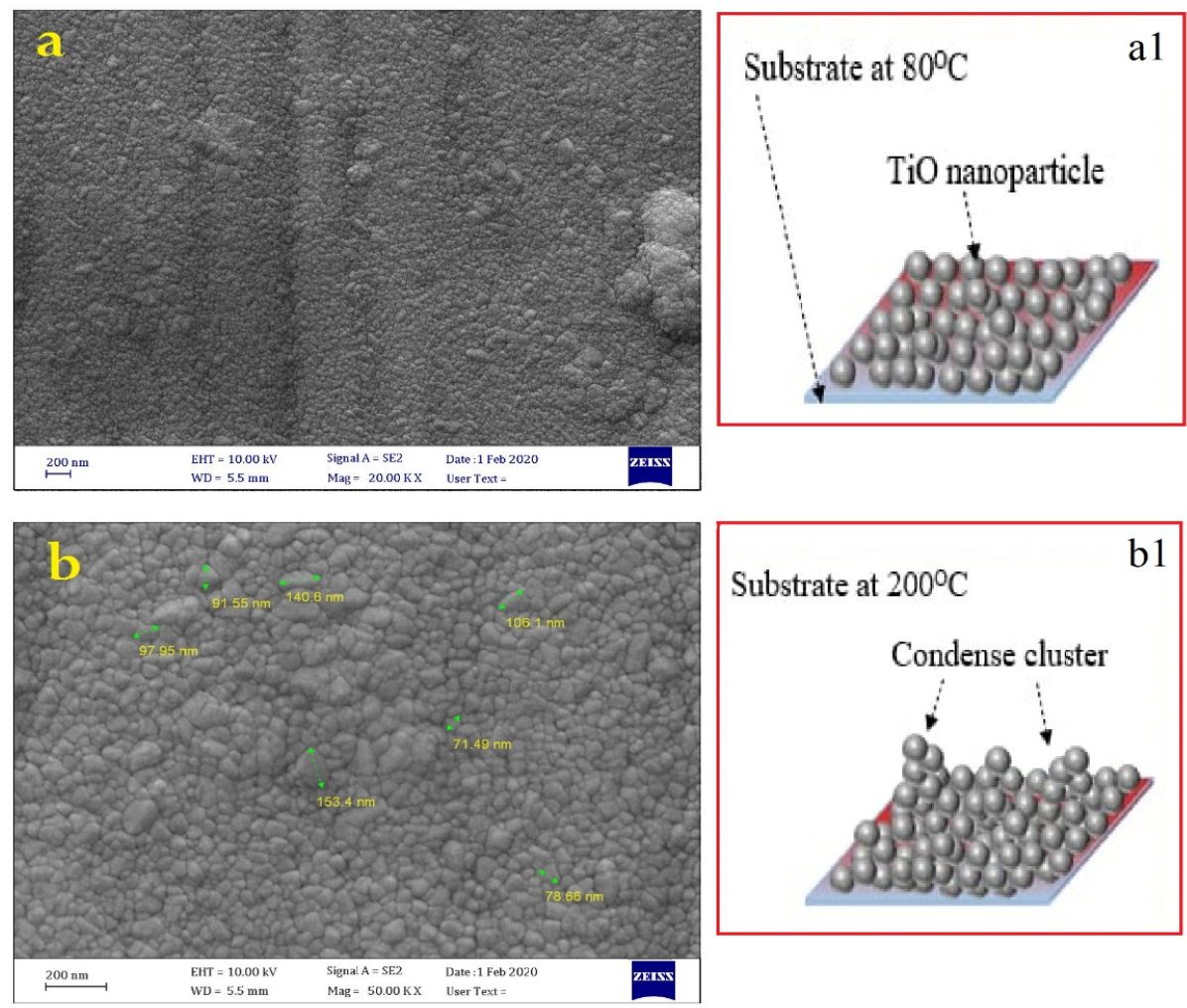

Substrate at $200^{\circ} \mathrm{C}$
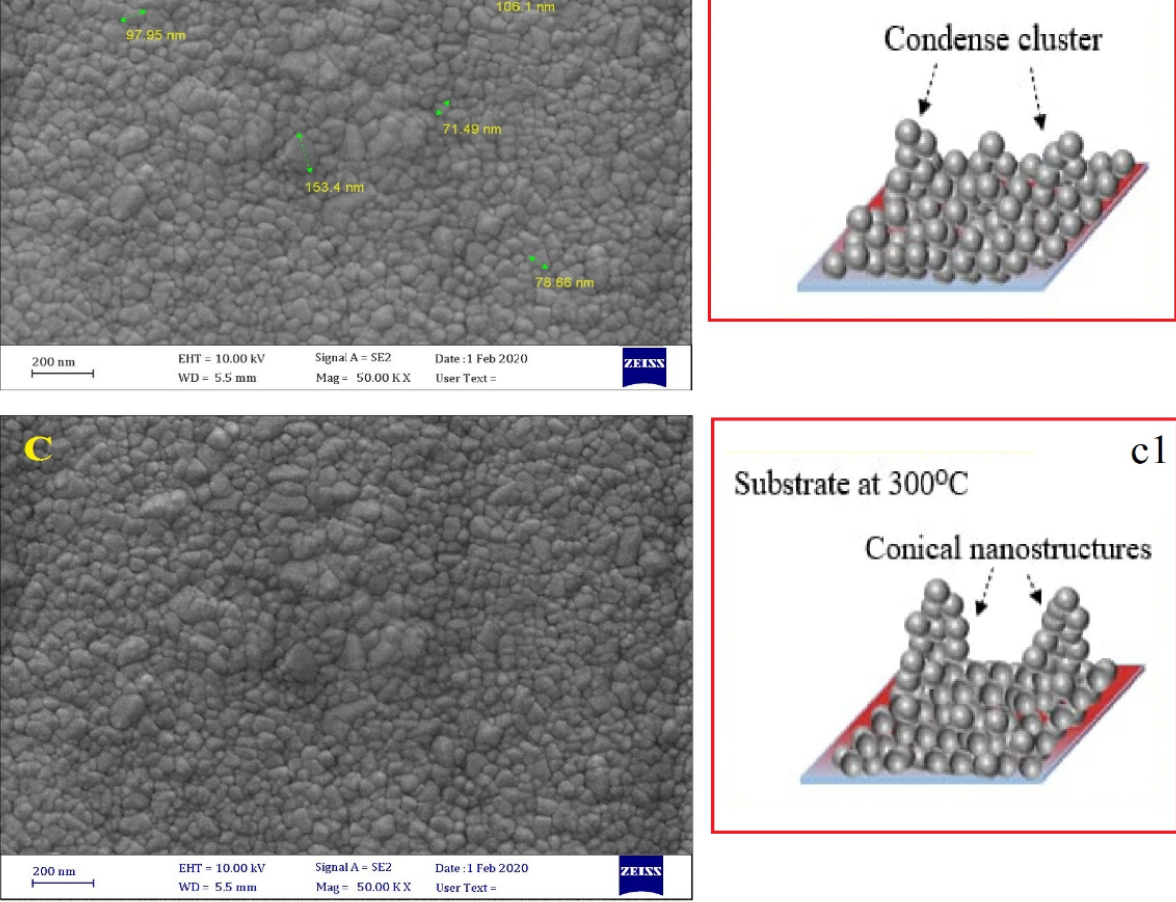

Substrate at $300^{\circ} \mathrm{C}$
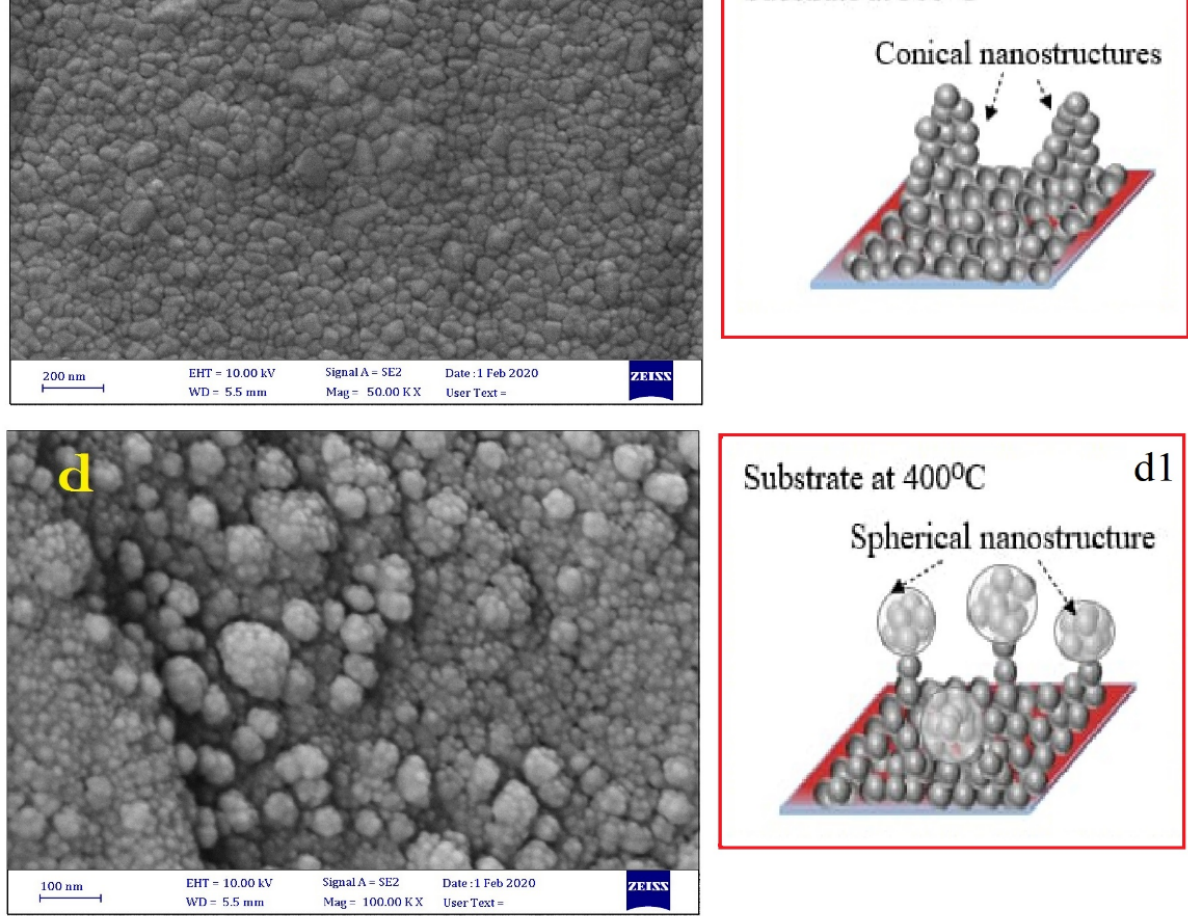

Spherical nanostructure

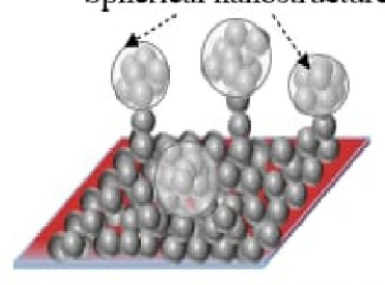

Figure 3: SEM images and schematic grain of TiO (a and a1) at $80^{\circ} \mathrm{C}$ (as deposited), (b and b1) at $200^{\circ} \mathrm{C}$, ( $\mathrm{C}$ and $\mathrm{c} 1$ ) at $300^{\circ} \mathrm{C}$ and (d and d1) at $400^{\circ} \mathrm{C}$ 

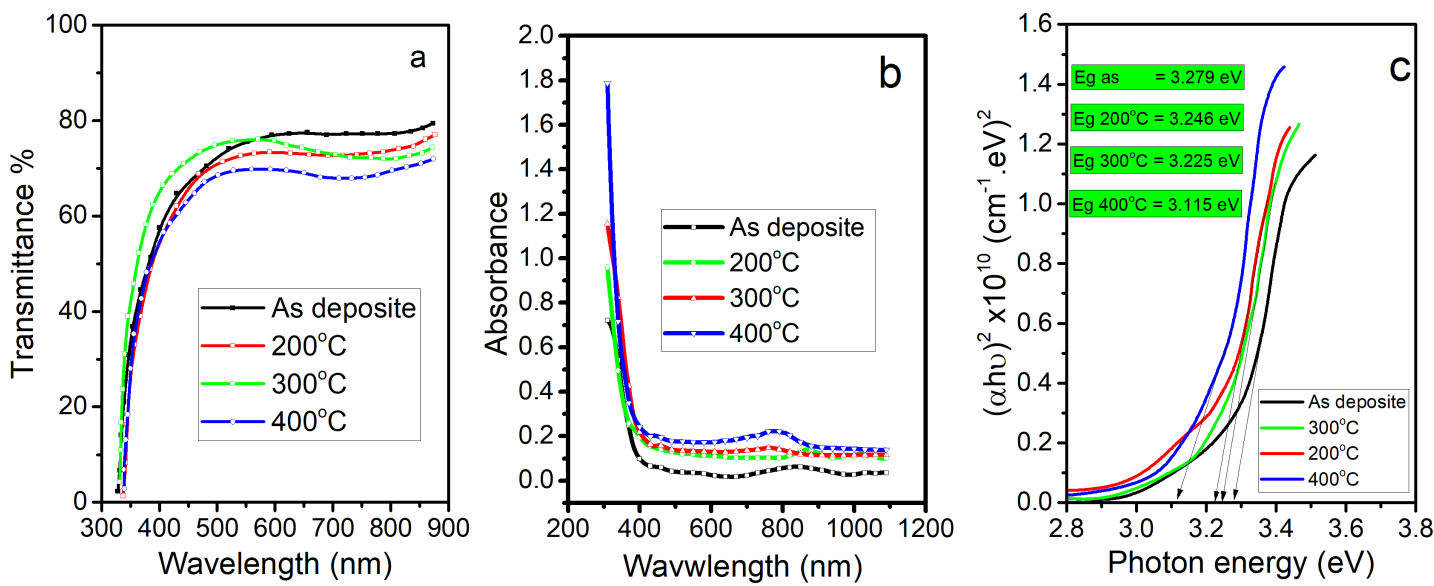

Figure 4: $(\mathrm{a}$ and $\mathrm{b})$ The transmittance and absorbance spectra, respectively, as a function of the wavelength, (c) $(\alpha \mathrm{h} v)^{2}$ as a function of the Photon energy of TiO at different annealing temperature

evaporation under vacuum at a temperature of $80^{\circ} \mathrm{C}$ (as deposited), and for samples annealed at 200,300 , and $400^{\circ} \mathrm{C}$ for $1 \mathrm{~h}$. From the initiation of the film deposition on the surface of the substrate at $80^{\circ} \mathrm{C}$, the first nuclei begin to form as clusters with a homogeneous surface due to the low temperature as shown in Figures 3(a) and 3(a1). Figures 3(b) and $3(\mathrm{~b} 1)$ represent the increase in annealing to $200^{\circ} \mathrm{C}$, which is considered low temperature. The nuclei combine with their neighbours to form condensed clusters within a homogeneous layer. This is due to the availability of sufficient thermal energy to move these particles and increase the surface energy of the preferred reflection (200), which makes the atoms cluster together. Figures 3(c) and 3(c1) show that with the increase of the annealing temperature to $300^{\circ} \mathrm{C}$, the size of these grains increased, and the shape of the nanostructures changed from a condensed cluster distribution to a conical structure. Figures 3(d) and 3(d1) show TiO films annealed at $400^{\circ} \mathrm{C}$, in which all the conical shapes are transformed into spherical shapes because of the re-evaporation of the deposited atoms with the increased annealing temperature.

Figures $4(\mathrm{a}$ and $\mathrm{b})$ presents the transmittance and $\mathrm{ab}$ sorbance spectrum as a function of the wavelength of titanium oxide prepared by thermal evaporation under vacuum at a temperature of $80^{\circ} \mathrm{C}$ (as deposited), and the samples annealed at 200,300 , and $400^{\circ} \mathrm{C}$ for $1 \mathrm{~h}$. The transmittance is reduced from $79.63 \%$ for the sample prepared at $80^{\circ} \mathrm{C}$ to $71.91 \%$ for the sample annealed at $400^{\circ} \mathrm{C}$, this can be attributed to the increase in the crystallite size reducing the grain boundaries. Consequently, the scattering of the incident rays is reduced. The transmittance was measured in the near-infrared region, making the annealed samples useful as an infrared window at wavelengths of 700-875 (nm).
Figure 4(c) presents the optical energy gap values for titanium oxide prepared by thermal evaporation under vacuum at a temperature of $80^{\circ} \mathrm{C}$ (as deposited) and the samples annealed at 200,300 , and $400^{\circ} \mathrm{C}$ for $1 \mathrm{~h}$. The optical energy gap values decrease from $3.279 \mathrm{eV}$ for the prepared sample at $80^{\circ} \mathrm{C}$ to $3.115 \mathrm{eV}$ for the sample annealed at $400^{\circ} \mathrm{C}$.

The optical energy gap can be estimated by plotting $(\alpha \mathrm{h} v)^{2} \mathrm{vs} \mathrm{h} v$ and then extrapolating the linear portion of the plot to the photon energy axis. Here, all values can be linked, as changing the particle size and the nanostructures influence the optical properties. Note that the increase in annealing temperature led to an increase in the clusters of atoms due to the increase in surface energy, and thus a decrease in the transmittance spectrum. This is made clear by the decrease in the energy gap values [18].

\section{Conclusions}

In the present work, titanium oxide was deposited in the TiO phase using the thermal evaporation method. Structural measurements of the as-deposited sample prepared at $80^{\circ} \mathrm{C}$ and the annealed samples at 200,300 , and $400^{\circ} \mathrm{C}$ show polycrystalline anatase structures. A single orientation in the (200) plane dominates for all samples, and the grain size increases from 16.89 to 30.88 (nm) with increased annealing temperature. Hemispherical and spherical nanostructures with a base length of $20(\mathrm{~nm})$ and a height of 45 $(\mathrm{nm})$ emerge with increased annealing temperature, and the propagation of these nanostructures is uniform over the entire area measured. The transmittance decreases from $79.63 \%$ to $71.91 \%$, and the energy gap value decreases from 
3.279 $\mathrm{eV}$ to $3.115 \mathrm{eV}$ when the annealing temperature is increased We conclude that increasing the annealing temperature can change the shape of the nanostructures formed on the surface, which allows tailoring the properties of TiO towards wider applications.

Acknowledgement: I would like to extend my thanks and appreciation to Mustansiriyah University, Faculty of Science, Advanced Materials Laboratory, as well as to the Ministry of Science and Technology for their contribution to the practical and theoretical part.

Funding: This work was received no external funding.

Author Contributions: Ahmed T. Hassan, Ehssan S. Hassan and Oday M. Abdulmunem conceptualized the topic, tested the samples and approved the final manuscript.

\section{References}

[1] Sethy NK, Arif Z, Mishra PK, Kumar P. Green synthesis of $\mathrm{TiO}_{2}$ nanoparticles from Syzygium cumini extract for photo-catalytic removal of lead $(\mathrm{Pb})$ in explosive industrial wastewater. Green Process Synth. 2020;9(1):171-81.

[2] Liao C, Li Y, Tjong SC. Visible-light active titanium dioxide nanomaterials with bactericidal properties. Nanomaterials (Basel). 2020 Jan;10(1):124.

[3] Willander M, Nur O, Zhao QX, Yang LL, Lorenz M, Cao BQ, et al. Zinc oxide nanorod based photonic devices: recent progress in growth, light emitting diodes and lasers. Nanotechnology. 2009 Aug;20(33):332001.

[4] Iqbal M, Ali A, Ahmad KS, Rana FM, Khan J, Khan K, et al. Synthesis and characterization of transition metals doped $\mathrm{CuO}$ nanostructure and their application in hybrid bulk heterojunction solar cells. SN Appl Sci. 2019;1(6):1-8.

[5] Wang Z, Huang BJ, Zhang CW, Xu XJ, Wang PJ. The Electronic Structures and Optical Properties of Electron Tuned Fe-Doped $\mathrm{SnO}_{2}$ Materials. J Nanomater. 2015;19:2015.
[6] Lany S. Semiconducting transition metal oxides. J Phys Condens Matter. 2015 Jul;27(28):283203.

[7] Alsheheri SZ. Nanocomposites containing titanium dioxide for environmental remediation. Des Monomers Polym. 2021 Jan;24(1):22-45.

[8] Benčina $M$, Iglič A, Mozetič $M$, Junkar I. Metka Bencina, Aleš Igli, Miran Mozeti and Ita Junkar 1 Crystallized $\mathrm{TiO}_{2}$ Nanosurfaces in Biomedical Applications. Nanomaterials (Basel). 2020;10(6):1121.

[9] Zhang B, Cao S, Du M, Ye X, Wang Y, Ye J. Titanium dioxide $\mathrm{TiO}_{2}$ mesocrystals: Synthesis, growth mechanisms and photocatalytic properties. Catalysts. 2019;9(1):91.

[10] Gonçalves MC, Pereira JC, Matos JC, Vasconcelos HC. Photonic band gap and bactericide performance of amorphous solgel titania: an alternative to crystalline $\mathrm{TiO}_{2}$. Molecules. 2018 Jul;23(7):1677.

[11] Simionescu OG, Romaniţan C, Tutunaru O, Ion V, Buiu O, Avram A. $\mathrm{RF}$ magnetron sputtering deposition of $\mathrm{TiO}_{2}$ thin films in a small continuous oxygen flow rate. Coatings. 2019;9(7):442.

[12] Lee C, Bae S, Park H, Choi D, Song H, Lee H, et al. Properties of Thermally Evaporated Titanium Dioxide as an Electron-Selective Contact for Silicon Solar Cells. Energies. 2020;13(3):678.

[13] Sahoo M, Yadav AK, Ghosh S, Jha SN, Bhattacharyya D, Mathews T. Structural studies of spray pyrolysis synthesized oxygen deficient anatase $\mathrm{TiO}_{2}$ thin films by using $\mathrm{X}$-ray absorption spectroscopy. Phys Chem Chem Phys. 2019 Mar;21(11):6198-206.

[14] Hadi EH, Abbsa MA, Khadayeir AA, Abood ZM, Habubi NF, Chiad SS. Effects of Mn doping on the characterization of nanostructured $\mathrm{TiO}_{2}$ thin films deposited via chemical spray pyrolysis method. J Phys Conf Ser. 2020;1664(1):12069-74.

[15] Chiad SS, Mubarak TH. The Effect of Ti on Physical Properties of $\mathrm{Fe}_{2} \mathrm{O}_{3}$ Thin Films for Gas Sensor Applications, 2020. Int J Nanoelectron Mater. 2020;13(2):221-32.

[16] Aljawfi RN, Alam MJ, Rahman F, Ahmad S, Shahee A, Kumar S. Impact of annealing on the structural and optical properties of $\mathrm{ZnO}$ nanoparticles and tracing the formation of clusters via DFT calculation. Arab J Chem. 2020;13(1):2207-18.

[17] Ravadgar P, Horng RH, Yao SD, Lee HY, Wu BR, Ou SL, et al. Effects of crystallinity and point defects on optoelectronic applications of $\beta-\mathrm{Ga}_{2} \mathrm{O}_{3}$ epilayers. Opt Express. 2013 Oct;21(21):24599-610.

[18] Sankar S, Gopchandran KG. Effect of annealing on the structural, electrical and optical properties of nanostructured $\mathrm{TiO}_{2}$ thin films. Cryst Res Technol. 2009;44(9):989-94. 